\title{
Potential of Digital Elevation Topographic Maps reveal the history of the region: comparing Those Maps with Marsh data in the early Meiji Period
}

\author{
Masatoshi Ideto a, ${ }^{\text {a }}$, Yuki Kurisu, Hideyuki Toishigawa \\ ${ }^{a}$ Geospatial Information Authority of Japan, Tsukuba, Ibaraki, Japan; ideto-m96dg@mlit.go.jp \\ * Corresponding author
}

Keywords: Digital Elevation Topographic Maps, Marsh data in the early Meiji Period, Thematic maps, GSI Maps

\begin{abstract}
:
Landform of lowland is remains of the natural disasters and the history. Residents of this area are influenced of the landform with history of natural disaster. Therefore, there is an inseparable relationship between topography and social life. At Geospatial Information Authority of Japan (GSI), we are creating Thematic maps which clearly express topographic information. We also create, Thematic maps which distinguish the topography from the formation of the land. New findings can be obtained by considering these thematic maps in combination.
\end{abstract}

In this paper, we study the relationship between landform and history of Tokyo by comparing "Digital Elevation Topographic Map" and "Marsh data in the early Meiji Period". (This early Meiji Period here is the 1880s.)

"Digital Elevation Topographic Map" is a topographic map in which a color shaded map and a GSI Map are superimposed. (The color shaded map is a drawing in which the areas with high elevations are warm colors and the areas with low elevations are cool colors, and further shaded.) Since the shadows are expressed based on elevation data, the terrain can be viewed three-dimensionally though it is on a plane.

"Marsh data in the early Meiji Period" is a distribution of land use at that time extracted from a topographic map created by Japanese Imperial Land Survey (former GSI) in the 1880s. The low wetlands in the Marsh data in the early Meiji Period are land uses that are considered to be closely related to liquefaction of the land, such as river, swamp, paddy field, reeds of the colony and so on.

We compared "Digital Elevation Topographic Map" which expressed detailed topography on the lowland along the Arakawa River from Eastern edge of Musashino Terrace (Figure 1) with "Marsh data in the early Meiji Period" (Figure 2 ), and considered it as follows together with the regional history:

1) Direction of river flow change (Sumida River is formerly Arakawa River.)

The flow path of the Arakawa River has a difference between the 1880s and the present, and it can be seen that the river improvement project has been carried out by the flood control project until now. The boundaries of the current city are along the Arakawa river flow in the 1880s, so it is possible to take a look at the remnants of those days. If you look at the current Arakawa River on the Digital Elevation Topographic Map, you can also read that a high standard levee (super levee) is being developed. In addition, the former Arakawa River before the river channel change is currently left as the Sumida River.

2) A Water area (Landfill proceeds in the sea.)

From the fact that many are Water area, as shown in Figure 2, it can be seen that reclamation has progressed from the 1880 s to the present, in many of the areas along the sea where facilities such as a Miraikan are constructed.

3) A Lowland (Distribution of Paddy field in the area between Edogawa River and Eastern edge of Musashino Terrace)

From the Figure 1, it can be understood that a large lowland spreads when looking at the area between the Edogawa River and Eastern edge of Musashino Terrace. If you look at the Figure 2 for the same area, it can be read that it corresponds roughly to Paddy field. However, Tokyo Station and its surrounding area has high altitude and Paddy field cannot be seen.

From the above, it is considered that the social life of the local residents developed in response to the urbanization taking into consideration the natural disaster risk while making good use of the topography characteristics. 
We gained the significance of better understanding the Thematic map and deepening the regional understanding by comparing the "Digital Elevation Topographic Map" and "Marsh data in the early Meiji Period". In the area where we currently live, area has various area-specific natural disaster risks. The topographic feature information possessed by GSI also leads to the understanding of natural disaster risk from natural geographical aspects while overviewing regional features. It is thought that the above things can contribute to the improvement of the regional disaster prevention ability in cooperation with disaster prevention education in the future.

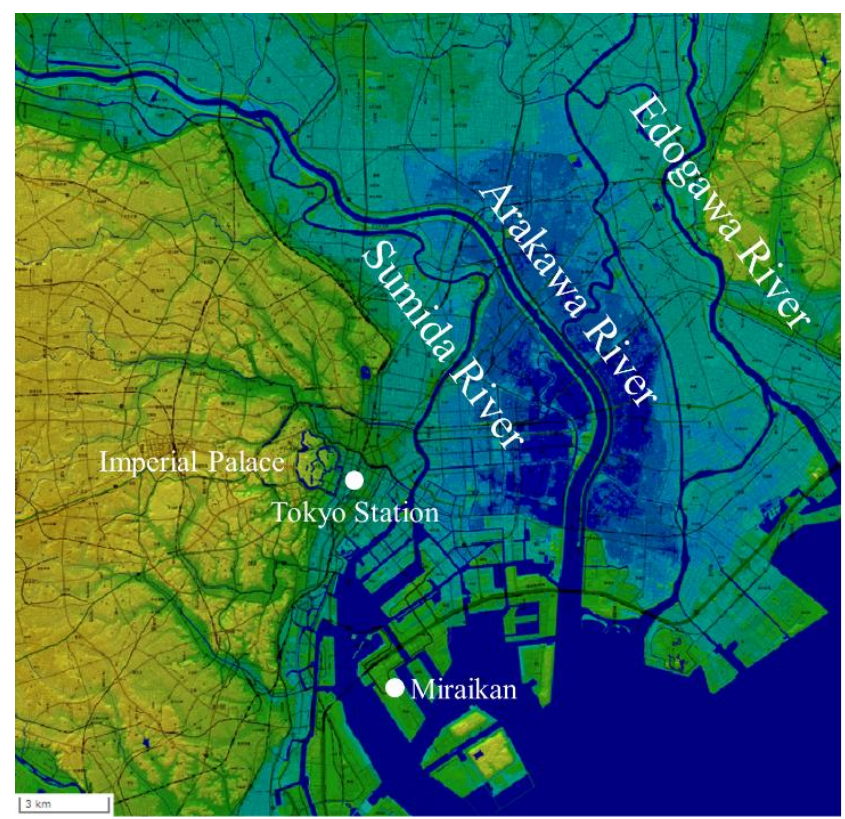

Figure 1. Digital Elevation Topographic Map-Tokyo (Excerpt)

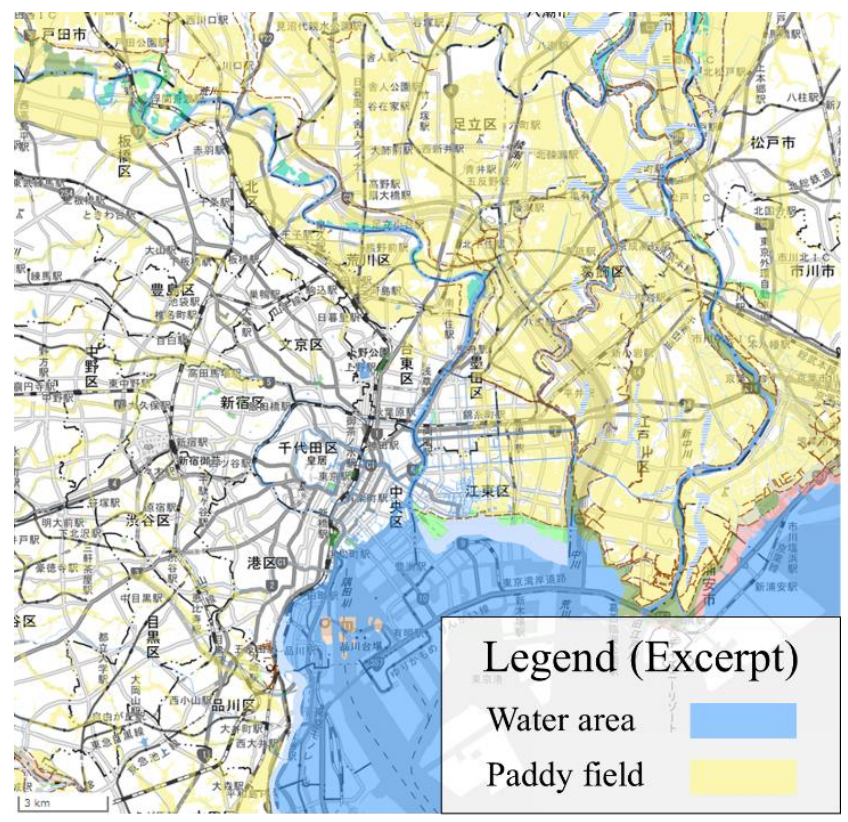

Figure 2. Marsh data in the early Meiji Period (Superimposed in GSI Map)

\section{Reference :}

Digital Elevation Topographic Map: Tokyo, D-No.866, 2017, GSI

Marsh data in the early Meiji Period: http://www.gsi.go.jp/bousaichiri/lc_meiji.html

GSI Maps: https://maps.gsi.go.jp/\#5/36.104611/140.084556/\&base=std\&ls=std\&disp=1\&vs=c1j0h0k010u0t0z0r0s0f1 